\title{
The Use of a Ti-Ni Shape Memory Alloy Ring Bone Fixator During the Retrograde Nailing of Supracondylar Femoral Fractures
}

\author{
Hyuk-Soo Han, MD, PhD, Dae-Ha Kim, MD and Seung-Baik Kang, MD, PhD \\ Department of Orthopaedic Surgery, SMG-SNU Boramae Medical Center, Seoul National University College of Medicine, Seoul, Korea
}

Purpose: To identify the effects of using a Ti-Ni shape memory alloy ring shaped bone fixator (SMA-rBF) during the retrograde nailing of supracondylar femoral fractures.

Materials and Methods: The authors reviewed 25 patients with a supracondylar femoral fracture treated by retrograde intramedullary nailing with or without SMA-rBF (group S, 12/25; group N, 13/25). Radiological measurements of angular deformity were performed and functional assessments were made using the Sanders grading system.

Results: All fractures healed after an average of 12.2 weeks (range, 9-15 weeks) in group N and after 11.6 weeks (range, 10-13 weeks) in group S $\left(\mathrm{p}=0.351\right.$ ). The mean angle of coronal angular deformity was valgus $0.8^{\circ}$ (range, varus $2.3^{\circ}$-valgus $4.5^{\circ}$ ) in group $\mathrm{N}$ and valgus $0.7^{\circ}$ (range, varus $1.0^{\circ}$-valgus $2.4^{\circ}$ ) in group $\mathrm{S}\left(\mathrm{p}=0.892\right.$ ). The mean angle of sagittal angular deformity was $1.0^{\circ}$ in extension (range, flexion $3.2^{\circ}$-extension $3.1^{\circ}$ ) in group $\mathrm{N}$ and $0^{\circ}$ (range, flexion $2.1^{\circ}$-extension $1.2^{\circ}$ ) in group $\mathrm{S}(\mathrm{p}=0.022$ ). However, functional grading evaluations revealed no differences between the two groups.

Conclusions: When reduction of a distal femoral fracture with retrograde nailing was difficult additional mini-open reduction and fixation with a ring shaped SMA did not delay or prevent bony union and resulted in good postoperative alignment.

Key words: Femoral supracondylar fracture, Retrograde nailing, Ti-Ni, Internal fixator, Alignment.

\section{Introduction}

Retrograde nailing is an effective and increasingly more popular method of distal femoral fracture fixation ${ }^{1-4)}$, and has been shown to produce good clinical outcomes ${ }^{5-10)}$. However, concern remains regarding potential articular damage and angular deformities

Received July 23, 2011; Revised (1st) August 18, 2011;

(2nd) November 6, 2011; Accepted November 8, 2011.

Correspondence to: Seung-Baik Kang, MD, PhD.

Department of Orthopaedic Surgery, SMG-SNU Boramae Medical

Center, Seoul National University College of Medicine,

20 Boramae 5th road, Dongjak-gu, Seoul 156-707, Korea.

Tel: +82-2-870-2200, Fax: +82-2-870-2709

Email: ossbkang@gmail.com

This is an Open Access article distributed under the terms of the Creative Common Attribution Non-Commercial License (http://creativecommons.org/licenses/by-nc/3.0/) which permits unrestricted non-commercial use, distribution, and reproduction in any medium, provided the original work is properly cited.

Copyright $\odot$ 2011. KOREAN KNEE SOCIETY

www.jksrr.org for comminuted or incompletely reduced fractures ${ }^{11)}$. To avoid intraarticular damage, we have no other choice for the entry point according to the individual anatomy of distal femur, which may cause angular deformities at fracture sites. Periarticular angular deformities are more likely to have a greater effect on the proximate joint than malunions at the diaphyses of the femur. To obtain more accurate reduction using intramedullary nailing, the cerclage technique can be used ${ }^{12)}$. However, extended soft tissue dissection for cerclage with wiring can compromise blood supply to fracture sites.

Titanium-nickel memory alloys (Ti-Ni SMAs) have biomechanical characteristics that are similar to those of bone, e.g., in terms of thermal shape recovery, superelasticity, biocompatibility, corrosion resistance, and damping properties, which makes alloys of this type interesting for medical applications ${ }^{13,14)}$. Furthermore, Ti-Ni SMA bone fixators present a useful alternative to the materials currently used to treat fractures. In the present study, we developed a Ti-Ni SMA bone fixator with an optimal transformation temperature $\left(\mathrm{Af}=35^{\circ} \mathrm{C} \pm 2^{\circ} \mathrm{C}\right)$ for human applications $^{15)}$. Using this material, we designed a Ti-Ni SMA ring shaped bone fixator (SMA-rBF, Bio-Smart, Ulsan, Korea) 


\section{Han et al. Ti-Ni Shape Memory Alloy Ring with Retrograde Nailing of Femur}

and applied this over the periosteum to replace conventional cerclage with minimal soft tissue dissection. Approval for clinical investigation of this material was obtained from the Korean Food and Drug Administration.

The purpose of this study was to identify the effect of the devised SMA-rBF on postoperative alignments and union rates after retrograde nailing of distal femoral fractures.

\section{Materials and Methods}

During the period between February 2003 and May 2006 we treated 26 patients with a supracondylar fracture of the femur using the retrograde intramedullary nailing technique, and in the present study, we retrospectively reviewed the clinical documents and radiographs of these patients. One patient had died before this assessment was performed, and thus, 25 patients were available for evaluation. There were no statistically significant differences in patient demographics or injury characteristics between the groups at inception (Table 1). Patient ages varied between 19 and 84 years (average 61 years). Two fractures were the result of traffic accidents; one in a female polytrauma patient with fractures to her ipsilateral humerus, pelvis and thoracic spine, and a subarachnoidal hemorrhage following a motorbike accident, whereas the other patient suffered an accident while walking. Three patients had sustained a prior fracture of the ipsilateral proximal femur and had been treated by internal fixation with a plate, which precluded antegrade intramedullary nailing; one of these patients had osteogenesis imperfecta. Seven patients had previously undergone total knee arthroplasty to ipsilateral knees and had sustained a

Table 1. Patient and Injury Characteristics

\begin{tabular}{lccc}
\hline \multicolumn{1}{c}{ Characteristic } & $\begin{array}{c}\text { Group N } \\
(\mathrm{n}=13)\end{array}$ & $\begin{array}{c}\text { Group S } \\
(\mathrm{n}=12)\end{array}$ & p-value \\
\hline Mean age (y) & $61.3(19-82)$ & $61.1(24-84)$ & 0.98 \\
Gender (male : female) & $6: 7$ & $2: 10$ & 0.18 \\
Multiple trauma (n) & 0 & 1 & 0.29 \\
Mechanism & $1: 12$ & $1: 11$ & 0.95 \\
(high energy : low energy) & 5 & 2 & 0.23 \\
Periprosthetic fracture & 5 & 4 & 0.53 \\
AO/ASIF classification & 3 & 3 & \\
33-A1 & 3 & 5 & \\
33-A2 & 5 & & \\
33-A3 & & & \\
\hline
\end{tabular}

AO/ASIF: association for osteosynthesis/association for the study of internal fixation. periprosthetic supracondylar fracture due to a fall (Fig. 1). In these patients, femoral components near fracture sites were stable. The other twenty fractures occurred in patients aged over 42 after low energy traumas. Eleven fractures were of class A1, six were of $\mathrm{A} 2$, and eight were of $\mathrm{A} 3$ according to the association for osteosynthesis/association for the study of internal fixation ( $\mathrm{AO} /$ ASIF) classification. Twenty-two patients were treated using an AIM titanium supracondylar nail (DePuy ACE, Leeds, UK) and three patients were treated with a T2 supracondylar nail (Stryker Trauma, Schonkirchen, Germany).

All operations were performed by one senior surgeon with a tourniquet. With the patient placed in the supine position on a radiolucent table, a rolled towel was placed under the affected knee to maintain $40^{\circ}-50^{\circ}$ of flexion. In all the cases, closed reduction was attempted and nailing was done using a limited medial parapatellar approach. The intercondylar entry point in the notch or the slot of the femoral component was confirmed to protect the articular cartilage or implants during reaming and nail passage. The entry point was opened afterwards with an awl and a guide wire was inserted under $\mathrm{C}$-arm radiographic guidance. The medullary canal was sequentially reamed to 1 $\mathrm{mm}$ more than the selected nail diameter and the entry point up was reamed to 12 (for an AIM nail) or $14 \mathrm{~mm}$ (for a T2 nail). Soft tissues were protected from reamers using a retractor. The nail was countersunk approximately $3 \mathrm{~mm}$ under the articular surface, and we then checked mediolateral and anteroposterior alignments at the femoral fracture site. If angular malalignment exceeded five degrees despite several closed reduction trials, we attempted open reduction via a lateral approach using a ca. $5-\mathrm{cm}$ skin incision. To maintain reduction, one or two SMA-rBFs were used instead of cerclage wiring. SMA-rBFs were applied as follows. A fixator was first cooled in ice-cold saline (when cooled
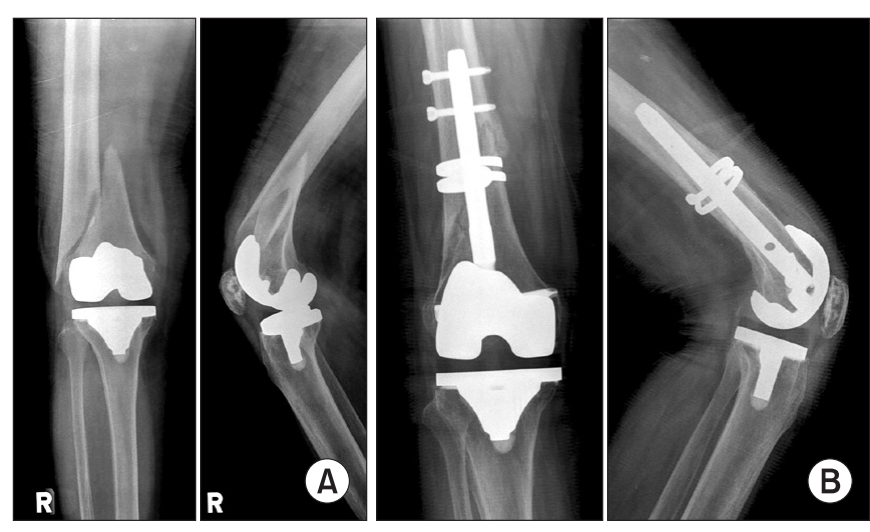

Fig. 1. (A) Preoperative anteroposterior and lateral radiographs of a periprosthetic fracture above a total knee arthroplasty. (B) Radiographs at postoperative 12th week. 
the fixator is malleable and easily uncoiled). Fixator sizes were determined either preoperatively from radiological images or intraoperatively based on direct measurements. An appropriately sized bone fixator was then applied to the reduced fracture site, and then irrigated with warm saline, which caused the fixator to contract to its original ring shape. After confirming that alignments are acceptable, the nail is locked with interlocking screws distally and proximally using an aiming device.

Mobilization was started on the first day postoperatively with continuous passive motion and active/active assisted quadriceps exercises. Partial weight bearing was allowed after early signs of callus formation (usually from the 6th postoperative week). Full weight bearing was permitted after complete union had been achieved.

Thirteen patients were treated by closed reduction and retrograde nailing (group $\mathrm{N}$ ), and 12 patients were treated by open reduction and additional internal fixation using a SMA-rBF (group S). Patients in groups $\mathrm{N}$ and $\mathrm{S}$ were followed regularly, and examined radiologically at 4,8 and 12 weeks, and at 6 months postoperatively and then annually when necessary. Fracture union was assessed using plain radiographs and was confirmed by the presence of bridging callus formation on anteroposterior and lateral radiographs and by the absence of pain at fracture sites during clinical examinations and weight bearing. Functional evaluations were performed using the Sanders' grading system ${ }^{16)}$, and angular deformities were measured in anteroposterior and lateral radiographs.

The Statistical Package for the Social Sciences (SPSS ver. 12.0, SPSS Inc., Chicago, IL, USA) was used for the analysis. Nonparametric comparisons were performed using the MannWhitney $U$ test. A p-values of $<0.05$ were deemed significant. This study was approved by the institutional review board of our hospital.

\section{Results}

Mean follow-up for patients in group $\mathrm{N}$ was 26.8 months (range, 12-96 months), whereas mean follow-up in group $\mathrm{S}$ was 25.9 months (range, 12-57 months). The type of fractures according to the AO/ASIF classification in group $\mathrm{N}$ were A1: 7 (54\%), A2: 3 (23\%), A3: 3 (23\%); and in group S were A1: 4 (33\%), A2: 3 (25\%), A3: 5 (42\%). The mean operative time in group $\mathrm{N}$ was 63 min (range, 55-80 min), which was shorter than that of group $\mathrm{S}$ (97 min; range, 82-120 min) ( $\mathrm{p}=0.001)$. One distal interlocking screw was used due to severe comminution in 2 cases of A3 type fractures in group $\mathrm{S}$, and two screws used in the other cases.
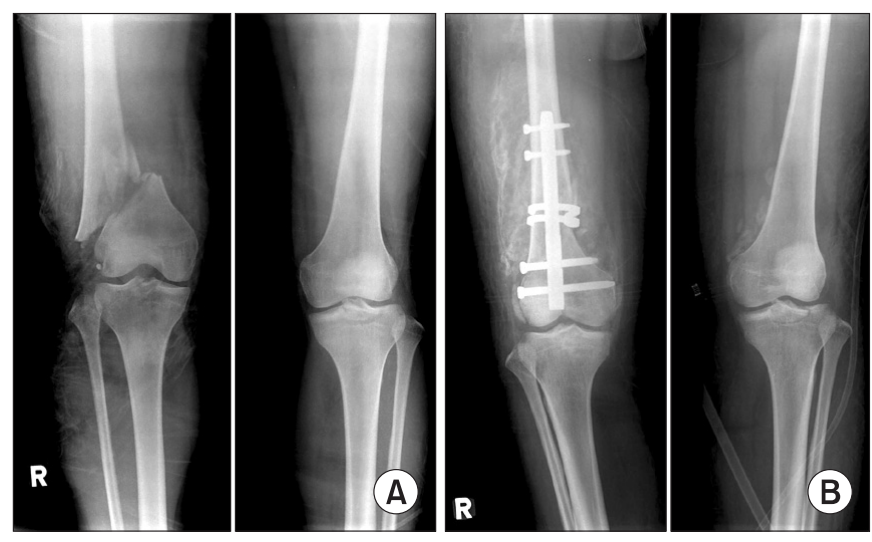

Fig. 2. (A) Preoperative anteroposterior radiograph of a 24-year-old female patient who had a subarachnoid hemorrhage and multiple fractures. (B) Heterotopic ossification was identified after retrograde intramedullary nailing and additional Ti-Ni shape memory alloy ring shaped bone fixator (SMA-rBF) fixation.

Fractures healed after an average of 12.2 weeks (range, 9-15 weeks) in group $\mathrm{N}$ and 11.6 weeks (range, 10-13 weeks) in group $\mathrm{S}(\mathrm{p}=0.351)$. Nail dynamization was performed in one patient in group N. Functional grading was similar in the two groups. According to Sanders' criteria, results were graded as excellent in $2(15 \%)$ patients in group $\mathrm{N}$ and in $2(17 \%)$ patients in group S; good in 7 (54\%) and 6 (50\%); fair in 4 (31\%) and 3 (25\%); and as poor in $0(0 \%)$ and $1(8 \%)$, respectively. Two patients in each group achieved a flexion of $<100^{\circ}$ and the others $\geq 100^{\circ}$. One case of heterotopic ossification was noted in group $S$ in a patient with a subarachnoid hemorrhage (Fig. 2). There were no cases of implant failure, knee sepsis, or deep or superficial infections.

Coronal alignments were similar in the two groups. The mean angle of coronal angular deformity was valgus $0.8^{\circ}$ (range, varus $2.3^{\circ}$-valgus $4.5^{\circ}$ ) in group $\mathrm{N}$ and valgus $0.7^{\circ}$ (range, varus $1.0^{\circ}$-valgus $\left.2.4^{\circ}\right)$ in group $\mathrm{S}(\mathrm{p}=0.892)$. However, mean angles of sagittal angular deformity were extension $1.0^{\circ}$ (range, flexion $3.2^{\circ}$-extension $3.1^{\circ}$ ) in group $\mathrm{N}$ and $0^{\circ}$ (range, flexion $2.1^{\circ}$-extension $1.2^{\circ}$ ) in group $\mathrm{S}$, which were significantly different $(p=0.022)$. There was no case of shortening or further angulation until complete union in both groups.

\section{Discussion}

Although the intramedullary nailing reduces the frequency of angular deformity for femur diaphyseal fractures, angular malalignment has been reported to occur at a frequency of up to $42 \%$ in studies on distal femoral metaphyseal fractures ${ }^{11,17,18)}$. These were mostly varus angulations caused by incomplete 


\section{Han et al. Ti-Ni Shape Memory Alloy Ring with Retrograde Nailing of Femur}

facture reduction, which is well known in distal femoral fractures because of adductor muscle pull, a laterally applied injury force, and medial comminution, which is commonly associated. When we perform total knee arthroplasty, we often use an intramedullary guide for the femur side. If there is femoral bowing, or even if not, we sometimes encounter cases requiring a femoral intramedullary guide entry point on the cartilage medial to the intercondylar notch to locate the guide at the center of the medullary canal. However, there is no compromise when nailing for a distal femoral fracture because of cartilage damage or the fixed TKA implant slot. In such cases, angulation of the distal fragment seems to be more common when the fracture is treated with a nail. Moreover, rotational malunion remains a problem after intramedullary nailing, which is not encountered during plating procedures ${ }^{19)}$. Furthermore, the intramedullary nailing method is less stable to varus-valgus loading than the plate method, although it provides adequate internal splinting for rapid healing and functional outcomes that are comparable to those of lateral fixation devices ${ }^{20,21)}$.

When distal femoral fractures cannot be accurately reduced by intramedullary nailing, several alternatives are available, i.e., acceptance of the malalignment, alteration of the fixation method from closed intramedullary nailing to open plate fixation, or additional mini-open reduction and cerclage wiring. Cases of diaphyseal femur fracture with more than $5^{\circ}$ of angulation are poorly corrected by remodeling, and limb mechanics are affected. However, for distal femoral metaphyseal fractures, alignment assessment is difficult, and few studies have been conducted on the outcome of malalignment.

The authors have performed the mini-open method when cases of malalignment and poor fracture fragment contact were encountered. The cerclage technique is sometimes required in unstable fractures or femoral fractures during total hip arthroplasty, especially during revisions ${ }^{22,23)}$. However, concerns have been expressed about additional periosteal dissection because of the possibility of disturbing the blood supply and causing non-union or delayed union. To minimize soft tissue dissection and injury to blood supply, we have used a ring shaped SMA instead of cerclage wiring. We found no case of non-union or delayed union in the $S$ group, which needed additional open reduction and SMA fixation. One case of heterotopic ossification was encountered, but this female patient was bed-ridden as a result of head trauma.

Our study has several limitations. It was retrospective and not randomized, and patient numbers were insufficient to perform statistical analysis, which precluded accurate comparisons.
In addition, the patients were heterogeneous and associated degenerative joint changes were not considered an outcome measurement. Yet, the described retrograde nailing method using an SMA has not been previously studied, and our study showed that when reduction of a distal femoral fracture with retrograde nailing was difficult additional mini-open reduction and fixation with a ring shaped SMA did not increase the risk of union delay or non-union and resulted in good postoperative alignment. However, no differences in functional outcomes were noted after an average follow-up of 26 months. A larger patient cohort and longer follow-ups are needed to assess the effect of alignment on clinical outcome.

\section{Conclusions}

When reduction of a distal femoral fracture with retrograde nailing was difficult additional mini-open reduction and fixation with a ring shaped SMA did not delay or prevent bony union and resulted in good postoperative alignment.

\section{References}

1. Martinet O, Cordey J, Harder Y, Maier A, Buhler M, Barraud GE. The epidemiology of fractures of the distal femur. Injury. 2000;31 Suppl 3:C62-3.

2. Zlowodzki M, Bhandari M, Marek DJ, Cole PA, Kregor PJ. Operative treatment of acute distal femur fractures: systematic review of 2 comparative studies and 45 case series (1989 to 2005). J Orthop Trauma. 2006;20:366-71.

3. Tornetta P 3rd, Tiburzi D. Antegrade or retrograde reamed femoral nailing. A prospective, randomised trial. J Bone Joint Surg Br. 2000;82:652-4.

4. Ricci WM, Bellabarba C, Evanoff B, Herscovici D, DiPasquale T, Sanders R. Retrograde versus antegrade nailing of femoral shaft fractures. J Orthop Trauma. 2001;15:161-9.

5. Gregory P, DiCicco J, Karpik K, DiPasquale T, Herscovici D, Sanders R. Ipsilateral fractures of the femur and tibia: treatment with retrograde femoral nailing and unreamed tibial nailing. J Orthop Trauma. 1996;10:309-16.

6. Sinha AK, Mani GV. Retrograde nailing for distal femoral fractures in Paget's disease. Injury. 1996;27:514-5.

7. Chin KR, Altman DT, Altman GT, Mitchell TM, Tomford WW, Lhowe DW. Retrograde nailing of femur fractures in patients with myelopathy and who are nonambulatory. Clin Orthop Relat Res. 2000;(373):218-26.

8. Kumar A, Jasani V, Butt MS. Management of distal femoral 
fractures in elderly patients using retrograde titanium supracondylar nails. Injury. 2000;31:169-73.

9. Armstrong R, Milliren A, Schrantz W, Zeliger K. Retrograde interlocked intramedullary nailing of supracondylar distal femur fractures in an average 76-year-old patient population. Orthopedics. 2003;26:627-9.

10. Weber D, Pomeroy DL, Schaper LA, Badenhausen WE Jr, Curry JI, Smith MW, Suthers KE. Supracondylar nailing of distal periprosthetic femoral fractures. Int Orthop. 2000;24:33-5.

11. Ricci WM, Bellabarba C, Lewis R, Evanoff B, Herscovici D, Dipasquale T, Sanders R. Angular malalignment after intramedullary nailing of femoral shaft fractures. J Orthop Trauma. 2001;15:90-5.

12. Ritter MA, Lutgring JD, Davis KE, Berend ME, Meding JB. A clinical, radiographic, and cost comparison of cerclage techniques: wires vs cables. J Arthroplasty. 2006;21:1064-7.

13. Berger-Gorbet M, Broxup B, Rivard C, Yahia LH. Biocompatibility testing of NiTi screws using immunohistochemistry on sections containing metallic implants. J Biomed Mater Res. 1996;32:243-8.

14. Ryhanen J, Niemi E, Serlo W, Niemela E, Sandvik P, Pernu H, Salo T. Biocompatibility of nickel-titanium shape memory metal and its corrosion behavior in human cell cultures. J Biomed Mater Res. 1997;35:451-7.

15. Nam TH, Chung DW, Kim JS, Kang SB. Phase transformation behaviors and shape memory characteristics of Ti-NiMo alloys. Mater Lett. 2002;52:234-9.

16. Sanders R, Swiontkowski M, Rosen H, Helfet D. Double- plating of comminuted, unstable fractures of the distal part of the femur. J Bone Joint Surg Am. 1991;73:341-6.

17. Johnson EE, Marroquin CE, Kossovsky N. Synovial metallosis resulting from intraarticular intramedullary nailing of a distal femoral nonunion. J Orthop Trauma. 1993;7:320-4.

18. Salem KH, Maier D, Keppler P, Kinzl L, Gebhard F. Limb malalignment and functional outcome after antegrade versus retrograde intramedullary nailing in distal femoral fractures. J Trauma. 2006;61:375-81.

19. Braten M, Terjesen T, Rossvoll I. Torsional deformity after intramedullary nailing of femoral shaft fractures. Measurement of anteversion angles in 110 patients. J Bone Joint Surg Br. 1993;75:799-803.

20. Firoozbakhsh K, Behzadi K, DeCoster TA, Moneim MS, Naraghi FF. Mechanics of retrograde nail versus plate fixation for supracondylar femur fractures. J Orthop Trauma. 1995;9:152-7.

21. Ito K, Grass R, Zwipp H. Internal fixation of supracondylar femoral fractures: comparative biomechanical performance of the 95-degree blade plate and two retrograde nails. J Orthop Trauma. 1998;12:259-66.

22. Teoh LC, Tan PL, Tan SH, Cheong EC. Cerclage-wiringassisted fixation of difficult hand fractures. J Hand Surg Br. 2006;31:637-42.

23. Fishkin Z, Han SM, Ziv I. Cerclage wiring technique after proximal femoral fracture in total hip arthroplasty. J Arthroplasty. 1999;14:98-101. 